\title{
A Case Report on The Child with Two Coins Ingested Foreign Bodies in The Esophagus During the Lockdown in COVID 19 Pandemic
}

\author{
Rabia Arora ${ }^{1}$, Satinder Pal Singh ${ }^{2 *}$ and Arvinder Singh Mann ${ }^{3}$ \\ ${ }^{1}$ Junior Resident, Department of Otolaryngology \& Head Neck Surgery, Government Medical College, India \\ ${ }^{2}$ Senior Resident, Department of Otolaryngology \& Head Neck Surgery, Government Medical College, India \\ ${ }^{3}$ Assistant Professor, Department of ENT \& Head Neck Surgery, GMC, India
}

*Corresponding author: Satinder Pal Singh, Senior Resident, Department of Otolaryngology \& Head Neck Surgery, Government Medical College, India

\begin{abstract}
A 4-year-old child presented to the emergency department with an acute onset of dysphagia and vomiting. A plain X-ray soft tissue neck lateral view revealed a double circular opacity in the cervical oesophagus consistent with an ingestion of multiple foreign bodies. Preoperative planning and SARS-CoV2 testing is of particular importance for the pediatric population and if testing cannot be performed, patients in all age groups should be handled as though they are positive for COVID-19, and appropriate precautions should be taken. The child was taken to the theatre for rigid pharyngo-oesophagoscopy and removal of the coins. After the first coin was removed subsequent endoscopic examination revealed a second coin at the same location. This extremely rare case of two ingested coins becoming impacted with perfect radiological alignment, we would therefore advocate having a low threshold for performing a 'second look' endoscopy after removal of the first foreign body with postoperative X-rays.
\end{abstract}

Keywords: COVID-19 Pandemic; otolaryngology; foreign body coin

Abbreviations: PPE: Personal protective equipment; COVID-19: Coronavirus disease 2019; SARS-CoV-2: Severe acute respiratory syndrome coronavirus-2

\section{Introduction}

A global pandemic, COVID 19 has become a major concern across the world. Long term home isolation has potentially increased the risk of domestic accidents in children like lodgement of foreign bodies in Ear, Nose and Throat. Foreign bodies in the airway are commonly seen in the pediatric population [1,2]. Single coin is a very common foreign body found in esophagus, but paired coin foreign body occurrence is quite rare. When any patient has history of ingested foreign body, investigations are mandatory regardless of the age or apparent absence of signs and symptoms [3]. This paper reports a case of double coin lodgment in the esophagus.

\section{Case Report}

We report a case of 4-year-old female child who presented to Department of otolaryngology, Government Medical College, Amritsar, Punjab, North India with the complaints of multiple episodes of vomiting, throat pain and foreign body sensation since 12-14 hours. There was no history of respiratory distress. As per patient's father child was apparently alright and playing at home. Then suddenly she started vomiting and was quite frightened with pale look. She had three episodes of vomiting further which consisted of food particles mainly. On further enquiry and prior 
assurance to patient she revealed that she kept coins in her mouth while playing. She also complained of foreign body sensation and she hid the truth due to fear of scolding. The patient presented in ENT emergency for diagnosis and management. On careful examination there was no abnormality in mouth and throat. Respiratory rate was normal. On auscultation air entry was bilaterally equal with no signs of cyanosis or adventitious sound. The radiograph of neck and chest in anteroposterior view revealed the disc shaped circular foreign body as suspected. But to our surprise the soft tissue radiograph of neck lateral view revealed foreign bodies in oesophagus at the level of seventh cervical vertebra (C7) and first thoracic vertebra (T1) which appeared to be double and superimposed because of irregularity of border of coin (Figure 1). Later under general anesthesia rigid esophagoscope was inserted and foreign body coin was visible. The foreign body was held with forceps and then both coins removed carefully avoiding damage to surrounding structures. No intra-operative complications were seen. As suspected from radiographs two coins i.e. one rupee and two-rupee coins stick with mucus were retrieved (Figure 2). The esophagus was inspected again. The patient was then kept under observation under antibiotic and analgesic cover. Postoperative event was uneventful. The patient was stable and discharged with adequate medical advice.
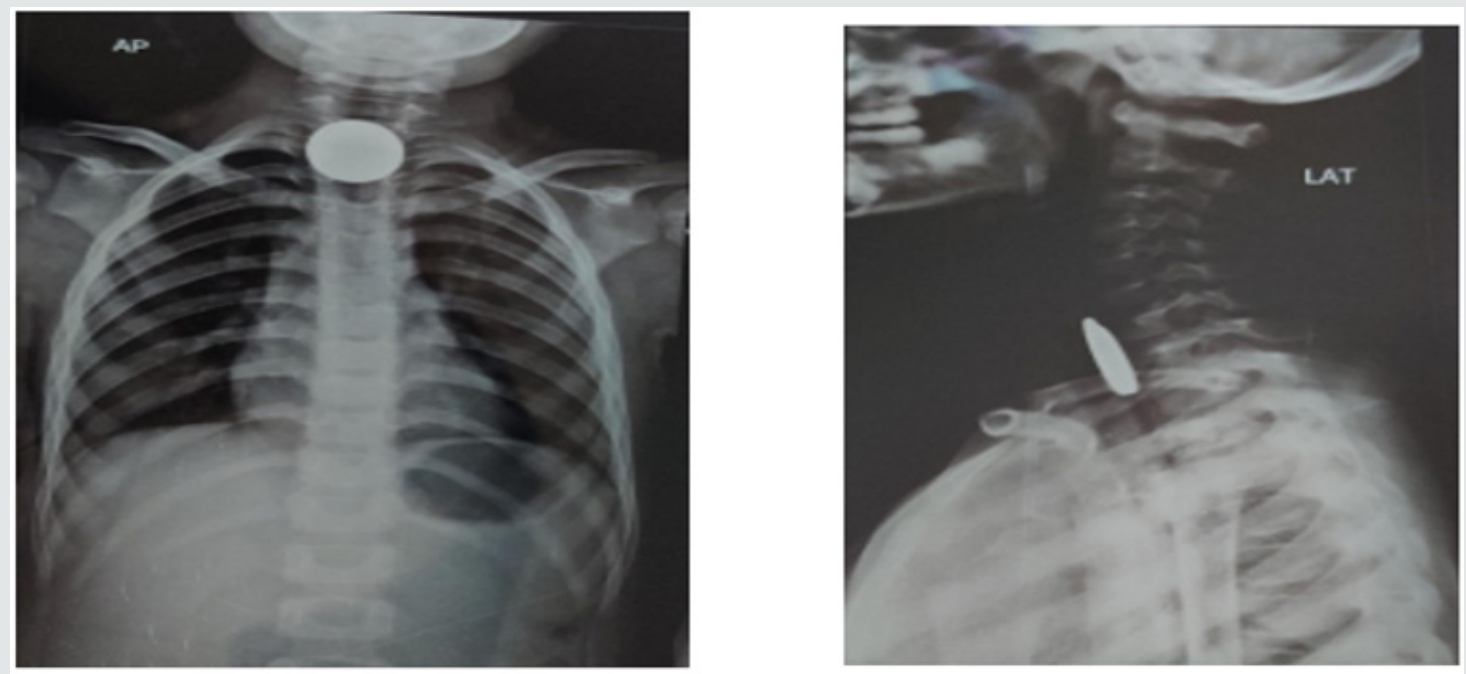

Figure 1: Radiograph of chest in anteroposterior single coin shadow and lateral view of Soft tissue neck showing double shadows of foreign body coins (Bigger coin anteriorly placed and smaller posteriorly).

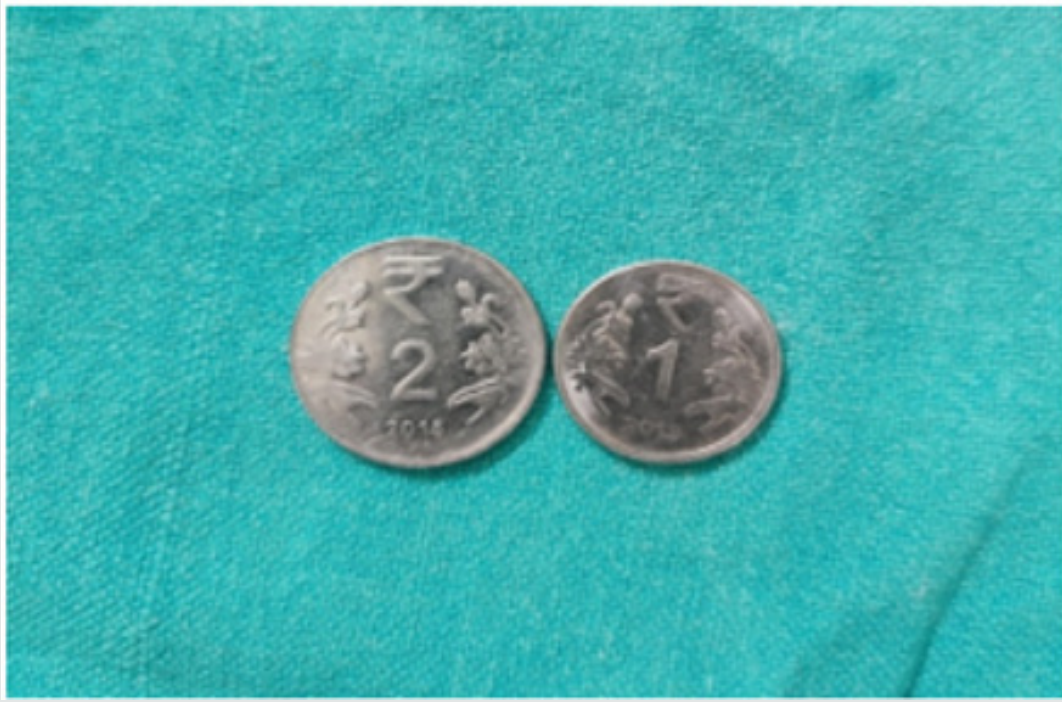

Figure 2: Foreign body two coins removed. 


\section{Discussion}

Foreign bodies in the throat are often medical emergencies that could potentially progress to surgical emergencies. Coins remain the most commonly ingested foreign body in children, accounting for as many as $60 \%$ of such cases [4]. Typically, coins become impacted in the proximal esophagus at the level of the crico pharynx [5] and removal within 24-48 hours is generally recommended [6]. The ingestion of multiple coins by children is a rare case. As per a clinical study two radiological views are recommended in the assessment of esophageal foreign bodies [7]. Radiographs of neck anteroposterior and lateral view soft view should be performed in cases of foreign body ingestion. Direct laryngoscopic visualization during intubation may reveal a proximal foreign object that can be removed with Magill forceps [8]. Complications include airway obstruction, laryngeal edema, and pushing the foreign body into the subglottic space, esophagus, or trachea [9]. Foreign bodies that are not removed may later result in infection or perforation.

Rigid esophagoscopy is a safe and effective procedure for foreign body esophagus. It should be done early to reduce mortality and morbidity. In present case rigid pharyngo-esophagoscopy was done under general anaesthesia and foreign body removal was performed with forceps. Acute complications of an impacted coin include oesophageal perforation, [10-12] respiratory distress and even death [13]. Long-term sequelae include formation of an esophageal structure [14] or tracheoesophageal fistula [15]. Early intervention is therefore paramount in preventing these lifethreatening complications, and identification of multiple coins is therefore paramount to avoid unnecessary complications that may arise from assuming the foreign body has been removed.

\section{Conclusion}

The foreign bodies should be carefully enquired while taking history and appropriate investigations should be done before reaching at final diagnosis. Serial radiograph could be advised if multiple foreign bodies are suspected to diagnose the exact location. Preoperative planning and SARS-CoV2 testing is of particular importance for the pediatric population and if testing cannot be performed, patients in all age groups should be handled as though they are positive for COVID-19, and appropriate precautions should be taken.

\section{References}

1. Heim SW, Maughan KL (2007) Foreign bodies in the ear, nose, and throat. Am Fam Physician 76(8): 1185-1189.

2. Baharloo F, Veyckemans F, Francis C, et al. (1999) Tracheobronchial foreign bodies: presentation and management in children and adults. Chest 115(5): 1357-1362.

3. Kay M, Wyllie R (2005) Pediatric foreign bodies and their management. Curr Gastroenterol Rep 7(3): 212-218.

4. Jackson RM, Hawkins DB (1986) Coins in the esophagus. What is the best management? Int J Pediatr Otorhinolaryngol 12(2): 127-135.

5. Amin MR, Buchinsky FJ, Gaughan JP (2001) Predicting outcome in pediatric coin ingestion. Int J Pediatr Otorhinolaryngol 59(3): 201-206.

6. Alrazzak BA, Al Subu A, Elitsur Y (2013) Etiology and management of esophageal impaction in children: a review of 11 years. Avicenna J Med $3(2): 33-36$.

7. Whelan Johnson S, Hall CE (2009) Multiple oesophageal foreign bodies: the importance of two radiological views. J Laryngol Otol 123(1): 121122 .

8. Soroudi A, Shipp HE, Stepanski BM (2007) Adult foreign body airway obstruction in the prehospital setting. Prehosp Emerg Care 11(1): 2529.

9. Puhakka H, Svedstrom E, Kero P, Valli P, Iisalo E (1989) Tracheobronchial foreign bodies. A persistent problem in pediatric patients. Am J Dis Child 143(5): 543-545.

10. Janik JS, Bailey WC, Burrington JD (1986) Occult coin perforation of the esophagus. J Pediatr Surg 21(9): 794-797.

11. Nahman B, Meuller C (1984) Asymptomatic esophageal perforation by a coin in a child. Ann Emerg Med 13(8): 627-629.

12. Tucker JG, Kim HH, Lucas GW (1972) Esophageal perforation caused by coin ingestion. South Med J 87(2): 269-72.

13. Byard RW, Moore L, Bourne AJ (1990) Sudden and unexpected death-a late effect of occult intraesophageal foreign body. Pediatr Pathol 10(5): 837-841.

14. Doolin EJ (1993) Esophageal stricture: an uncommon complication of foreign bodies. Ann Otol Rhinol Laryngol 102(11): 863-866.

15. Obiako MN (1982) Tracheoesophageal fistula: a complication of foreign body. Ann Otol Rhino Laryngol 91(3 Pt 1): 325-327. 
CC (i) This work is licensed under Creative Commons Attribution 4.0 License

To Submit Your Article Click Here: $\quad$ Submit Article

DOI: $10.32474 / \mathrm{SJ} 0.2020 .05 .000202$

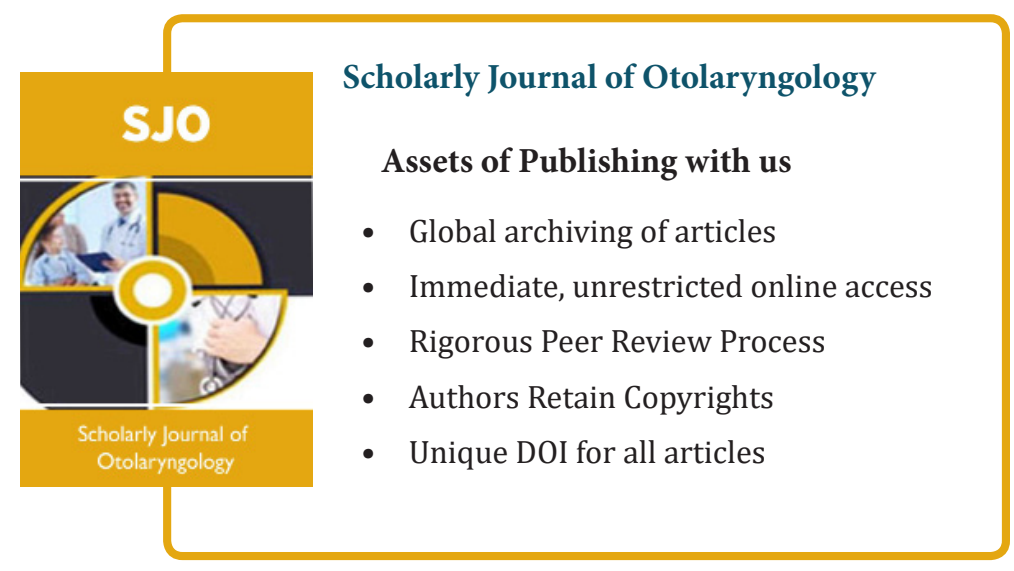

